\title{
eTank: A Decision Support Tool for optimizing rainwater tank size
}

\author{
$\underline{\text { M.A. Imteaz }}^{\text {a }}$, A. Rauf ${ }^{a}$ and M.A. Aziz ${ }^{a}$ \\ ${ }^{a}$ Faculty of Engineering and Industrial Sciences, Swinburne University of Technology, Hawthorn, VIC3122, \\ Melbourne, Australia. \\ Email: mimteaz@swin.edu.au
}

\begin{abstract}
One of several common water conserving techniques is on-site stormwater harvesting for nondrinking purposes. However there is a lack of knowledge on the actual cost-effectiveness and performance optimisation of any stormwater harvesting system. At present stormwater harvesting systems are proposed and installed without any in-depth analysis of its effectiveness in various climate conditions. In particular the proposed design storage volume could be overestimated or underestimated. The biggest limitation of stormwater harvesting schemes is the rainfall variability, which will control the size of the storage needed and can't be based on long-term average annual rainfall data. A stormwater harvesting system designed considering average annual rainfall will not provide much benefit for a critical dry period. Similarly, a stormwater harvesting design for a particular region will not be similar for stormwater harvesting design in other regions. With all these uncertainties, even with several awareness campaigns and financial incentives, there is a general reluctance to adopt any potential stormwater harvesting measure. The main reasons behind this are that people are not aware of the payback period for their initial investment and the optimum size of the storage required satisfying their performance requirements. It is necessary to quantify the expected amount of water that can be saved and used through any particular harvesting technique based on contributing catchment size, tank volume, geographic location, weather conditions and water demand. Without proper analysis and quantification, any adopted tank size may not be cost-effective. This paper presents development of a comprehensive decision support tool to analyse and optimize a potential rainwater tank. The tool was developed based on daily water balance analysis, incorporating daily rainfall, runoff generated from roof after losses, daily water demand, tank size and overflow from the tank. For insufficient/no rainwater, the analysis assumes augmented supply from townwater supply. The developed tool enables a simple quantitative analysis of the expected water that can be saved based on the relevant constraints. The input data require are: daily rainfall, roof area, expected loss from roof to tank, tank volume and daily rainwater demand. The tool produces graphs showing cumulative yearly rainwater used, overflow and augmented townwater supply. To account for climate variability, provision has been made in the tool to analyse for a particular option in three different years (climate conditions), for which often a dry year, an average year and a wet year are considered. Also, the tool enables a life cycle costing analysis and payback period of any particular proposed tank size through the simulated outputs related to expected water savings per year, initial construction costs and operational costs related to tank. Expected water savings are calculated by tanking average of three (dry, average and wet) separate year's cumulative annual water savings. For the cost analysis, additional input data require are: water price, water price increment rate and maintenance cost increment rate. Also, the tool calculates the reliability of a particular size tank, connected with a particular roof size to fulfill the expected rainwater demand. Reliability is a measure of percentage of days in a year, when the tank was able to supply the expected demand. The paper illustrates different scenario results produced by the tool for daily rainfall data near Melbourne City, under different climatic conditions. The simulated results were compared with an earlier published spreadsheet based model results. The developed tool and the earlier spreadsheet based model produce exactly same results. The developed tool is a userfriendly tool which will make end-users decision making process easy, effective and knowledgeable.
\end{abstract}

Keywords: Rainwater tank, daily water balance, climatic conditions, climate variability, reliability and life cycle costing 


\section{INTRODUCTION}

With increasing population and changing climate regime, water supply systems in many cities of the world are under stress. To tackle this problem, water authorities are adopting several measures including demand management and identifying alternative water sources such as stormwater harvesting, greywater and wastewater reuse and desalination. Among all the alternative water sources, stormwater harvesting perhaps has received the most attention. In Australia, government authorities have been promoting stormwater harvesting through campaigns, as well as offering incentives and grants to promote water saving ideas and innovations.

Among all the stormwater harvesting options, rainwater tanks have been widely studied. Fewkes (1999) conducted studies on residential rainwater tanks in the United Kingdom, producing a series of dimensionless design curves which allows estimation of the rainwater tank size required to obtain a desired performance measure given the roof area and water demand patterns. Vaes and Berlamont (2001) developed a model to determine the effectiveness of rainwater tanks and stormwater runoff using long term historical rainfall data. Coombes and Kuczera (2003) found that for an individual building with a $150 \mathrm{~m}^{2}$ roof area and $1-5 \mathrm{~kL}$ tank in Sydney can yield 10-58\% mains water savings (depending on the number of people using the building). According to Coombes and Kuczera (2003), depending on roof area and number of occupants, rainwater tank use can result in mains water annual savings of $18-55 \mathrm{~kL}$ for $1 \mathrm{~kL}$ sized tanks and $25-144 \mathrm{~kL}$ for $10 \mathrm{~kL}$ sized tanks. Ghisi et al. (2007 and 2009) investigated the water savings potential from rainwater harvesting systems in Brazil (South America) and found that average potential for potable water savings of 12-79\% per year for the cities analysed.

Despite positive outcome from many studies, there remains a general community reluctance to adopt stormwater harvesting on a wider scale. Part of the reason for this reluctance can be attributed to lack of information about the effectiveness of a stormwater harvesting system and the optimum storage size required to satisfy the performance requirements under the specific site conditions (Imteaz et al., 2011a). A proper indepth understanding of the effectiveness of any proposed on-site stormwater harvesting system is often lacking. The predicted change in rainfall patterns in Australia as a result of global warming adds further complexity to planning adequate rainwater harvesting schemes. Furthermore, many studies have used mean annual rainfall data or generated rainfall data in modelling rainwater harvesting system. In an area of highly inter-annual rainfall variability, analysis considering long-term mean annual rainfall is not useful.

Jenkins (2007) developed a computer model for the continuous simulations of amount of rainwater stored in the tank, amount of rainwater used, amount overflowed and amount of mainwater used to top up the tank for household rainwater tanks. The model was used for 12 major cities in Australia using daily rainfall data for the simulations of historical average amounts of the above-mentioned variables. Jenkins (2007) concluded that the climate characteristics of the site have a significant influence on the effectiveness of the rainwater tank. Khastagir and Jayasuriya (2010) introduced a variable named reliability of rainwater tanks and calculated it using a daily water balance model. They have presented contours of optimum tank sizes for surrounding areas of Melbourne, considering the historical daily rainfall, the demand for rainwater, the roof area for a supply reliability of $90 \%$. All of these analyses were based on historical daily rainfall data, making an average of cumulative historical savings and other variables. Through such analysis of averaged variables/parameters rainwater tank users do not get an actual range of expected outcomes. With the impacts of climate change, such ranges of actual outcomes are expected to be widen further. Imteaz et al. (2011b) have presented a detailed study for optimising rainwater tank sizes connected with large roofs for a location near central Melbourne.

Most of the above-mentioned studies were based on particular geographical area(s). The results would vary with geographical locatoins i.e. with different climatic conditions or in general with different rainfall intensities and pattern. In reality, there will be numerous optimal solutions with different combinations of storage volumes, roof sizes, rainwtaer demand and number of people in the household. A comprehensive decision support tool would be able to produce reliability, qumulative water savings, qumulative overflow losses and qumulative townwater supply used for any geographical location with any value of abovementioned variables. Also, to help potential users' to be able to take a well-informed decision, a life-cycle costing analysis including pay-back period calculation is necessary.

This paper presents development of a decision support tool for the optimisation of rainwater tank size, considering daily rainfall, losses, roof area, tank volume, rainwater demand and overflow losses. Also, the tool calculates pay-back period of a particular tank project, considering water price, water price increment rate, tank construction and maintenance costs, maintenance cost increment rate and expected average water savings (per year). 


\section{METHODOLOGY}

A daily water balance model was developed considering daily rainfall, contributing catchment (roof) area, losses due to leakage, spillage and evaporation, storage (tank) volume and water uses. Daily runoff volume is calculated from daily rainfall amount by multiplying the rainfall amount with the contributing roof area and deducting the losses (a single lumped loss value is considered to account for several losses i.e. leakage, spilling and evaporation). Generated runoff is diverted to the connected available storage tank. Available storage capacity is compared with the accumulated daily runoff. If the accumulated runoff is bigger than avaialble storage volume, excess water (overflow) is deducted from the accumulated runoff. Amount of water use(s) is deducted from the daily accumulated/stored runoff amount, if sufficient amount of water is available in the storage. In a situation, when sufficient amount of water is not avaialble in the storage, model considers that the remaining water demand is supplied from the town water supply. The model calculates daily stormwater use, daily water storage in the tank, daily overflow and daily town water use (if any). In addition, model calculates accumulated annual stormwater use, accumulated annual overflow and accumulated annual town water use. In this model, the prime input value is the daily rainfall amounts for a full year. As the prime objective was to compare different expected outcomes in different climatic conditions, model provides option to input daily rainfall data for three differeent years. Although, any three years can be selected, however this would be a reasonable practice to compare outcomes within dry, average and wet years.

The overall process can be mathematically described as follows:

Cumulative water storage equation,

$$
\begin{aligned}
& S_{t}=V_{t}+S_{t-1}-D \\
& S_{t}=0, \text { for } S_{t}<0 \\
& S_{t}=C, \text { for } S_{t}>C
\end{aligned}
$$

where, $S_{t}$ is the cumulative water stored in the rainwater tank $(\mathrm{L})$ after the end of $\mathrm{t}^{\text {th }}$ day, $V_{t}$ is the harvested rainwater (L) on the $\mathrm{t}^{\text {th }}$ day, $S_{t-1}$ is the storage in the tank (L) at the beginning of $\mathrm{t}^{\text {th }}$ day, $D$ is the daily rainwater demand (L), and $C$ is the capacity of rainwater tank (L).

Townwater use equation,

$$
T W=D-S_{t}, \text { for } S_{t}<D
$$

where, $T W$ is the townwater use on $\mathrm{t}^{\text {th }}$ day $(\mathrm{L})$.

Overflow equation,

$$
O F=S_{t}-C, \text { for } S_{t}>C
$$

where, $O F$ is the overflow on $\mathrm{t}^{\text {th }}$ day (L).

Reliability is calculated with the equaiton,

$$
R_{e}=(N-U) / N \times 100
$$

where, $R_{e}$ is the reliability of the tank to be able to supply intended demand (\%), $U$ is the number of days in a year the tank was unable to meet the demand, and $N$ is the total number of days in a particular year.

For the calculation of pay-back period, total construction and maintenance costs are calculated using the equation,

$$
C M C_{t+1}=C M C_{t}+\left(M C+M C^{*} M C I R^{*} t / 100\right)
$$

where, $C M C_{t+1}$ is the total construction and maintenance costs up to year ' $\mathrm{t}+1$ ', $C M C_{t}$ is the total construction and maintenance costs up to year ' $\mathrm{t}$ ', $M C$ is the maintenance cost in the base year (immediately after construction), MCIR is the maintenance cost increment rate (\%) from the base year and ' $t$ ' is the number of years after construction.

Price of water savings are calculated using the equation,

$$
W S_{t+1}=W S_{t}+X^{*}(Y+Y * Z * t / 100)
$$

where, $W S_{t+1}$ is the total price of water savings upto year ' $\mathrm{t}+1$ ', $W S_{t}$ is the total construction and maintenance costs up to year ' $\mathrm{t}$ ', $X$ is the average water savings per year (average of typical dry, average and wet years), $Y$ 
is the unit water price at the base year, $Z$ is the water price increment rate (\%) from the base year and ' $t$ ' is the number of years after construction.

Above costs and savings equations are calculated in consecutive years until the total savings exceeds the total costs. The pay-back period is expressed as less than a calculated number of years, when total savings exceeds the total costs.

\section{DEVELOPED TOOL}

Incorporating all the above-mentioned equations, an interactive decision support tool was developed. Figure 1 shows basic "Data Input" menu of the tool, through which all the preliminary data needs to be inserted. It requires data on: roof area, \% loss from the roof runoff, tank volume and daily rainwater demand. Towards the right side of the window it shows the format of rainfall data file. By pressing a button near the bottom, this window will upload the rainfall data file from a saved location. Eventually, pressing the "Calculate" button will initiate all the calculations related to daily stormwater use, daily water storage in the tank, daily overflow and daily town water use. Also, it calculates accumulated annual stormwater use, accumulated annual overflow and accumulated annual town water use. All these calculations are performed for three separate years, for which rainfall data is given. Figure 2 shows the menu for "Analysis Results". This menu presents graphical outputs for cumulative rainwater use, cumulative overflow loss and cumulative townwater use. Each graph shows results for three selected years. Specific output graph can be obtained by pressing corresponding button. Pressing "Show Reliability" button will initiate and show reliabilities in three different years (conventionally dry, average and wet years). Figure 3 shows the menu for "Cost Analysis". Right side of the menu shows calculated water savings in three different years. Also, it calculates average water savings. For the calculations of payback period, it requires some input data to be provided: current unit water price, water price increment rate, tank construction cost, current year tank maintenance cost and maintenance cost increment rate. Pressing "Payback Period" button will calculate and show payback period for a certain sized tank considering an average water savings from three typical years (dry, average and wet).

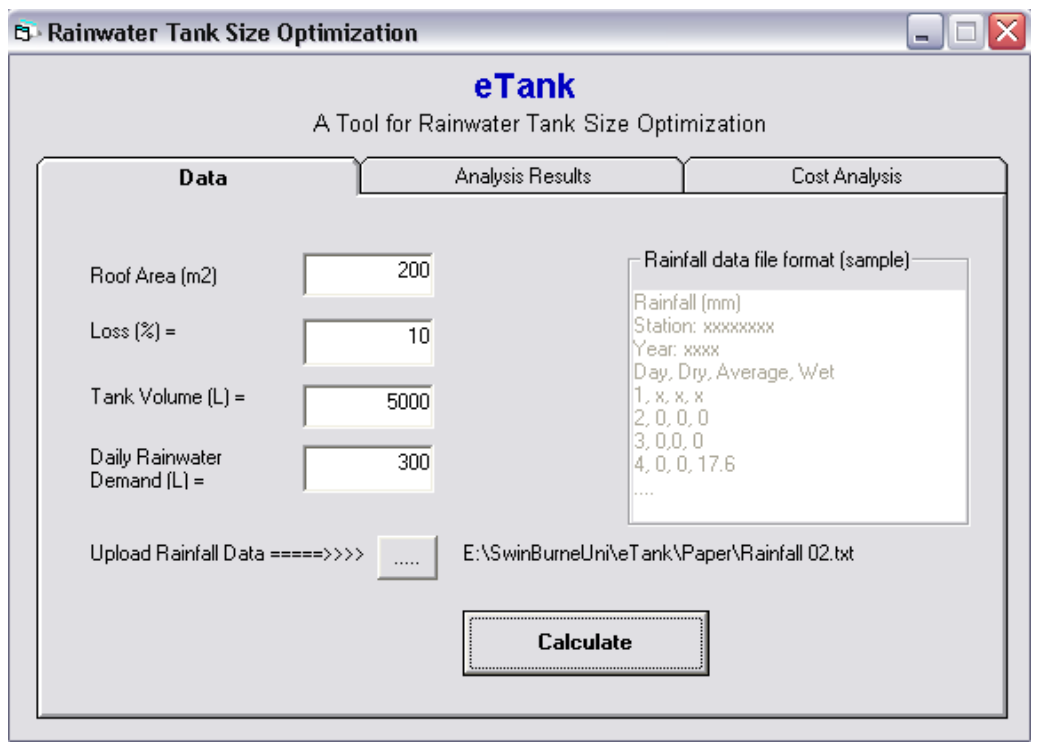

Figure 1 Basic data input menu

\section{TOOL OUTPUTS}

The developed tool was used for daily rainfall data for a station near Melbourne city (collected from Bureau of Meteorology). From historical rainfall data, it was found that year 1983 was having an average rainfall of $654 \mathrm{~mm}$ for the station. For clarity, a fictitious wet year daily rainfall data was created by multiplying 1.6 with the daily rainfall data of the average year. Similarly, a fictitious dry year daily rainfall data was created by multiplying 0.7 with the daily rainfall data of the average year. Other tank related physical data assumed as, tank volume of $5000 \mathrm{~L}$, rainfall loss of $10 \%$, daily rainwater demand of 300L and connected roof area of 200 $\mathrm{m}^{2}$. Figure 4 shows the graphs of cumulative rainwater used for the three typical years for the selected location. For the same typical years, Figure 5 and Figure 6 show the graphs of cumulative overflow loss from the tank and cumulative townwater used respectively. For the same data, calculated reliabilities are $62 \%$, $81 \%$ and $87 \%$ for the dry, average and wet years respectively. It is to be noted that with a $60 \%$ increase of 
rainfall (from average year to wet year), reliability is increased by $6 \%$ only. Whereas, with a $30 \%$ decrease of rainfall (from average year to dry year), reliability is decreased by $19 \%$. Calculated results were compared with the calculations of an earlier developed spreadsheet based model (Imteaz et al., 2011b). It is found that developed tool produced exactly same results as calculated by the spreadsheet based model.

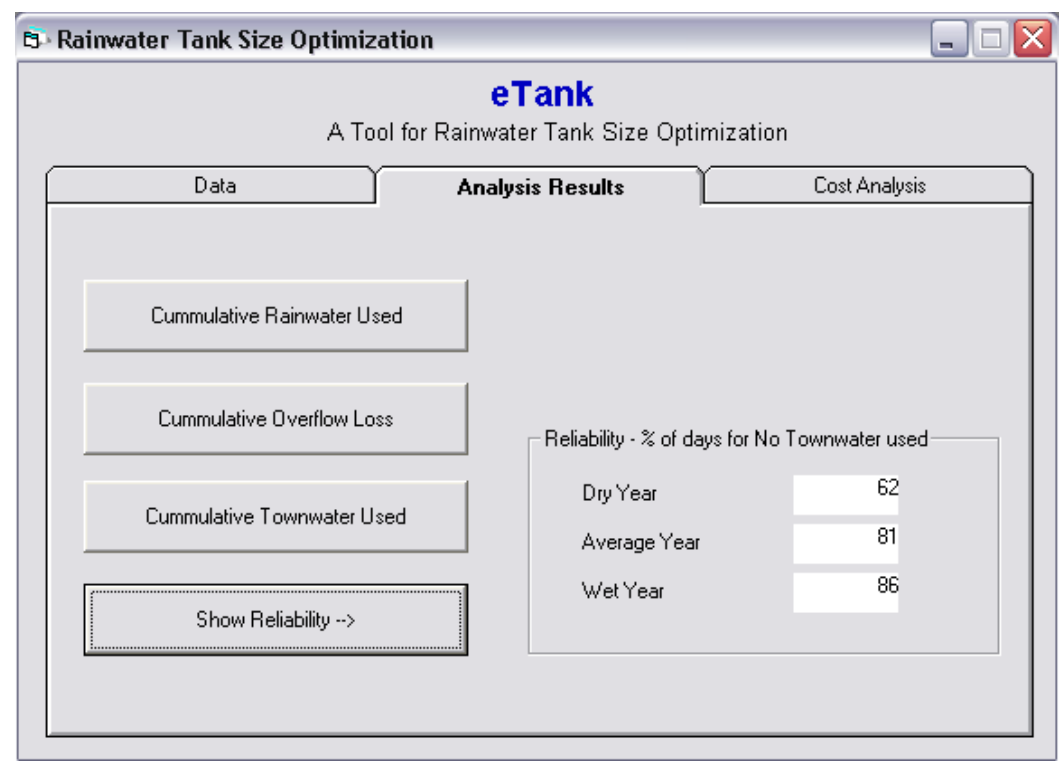

Figure 2 Analysis results menu

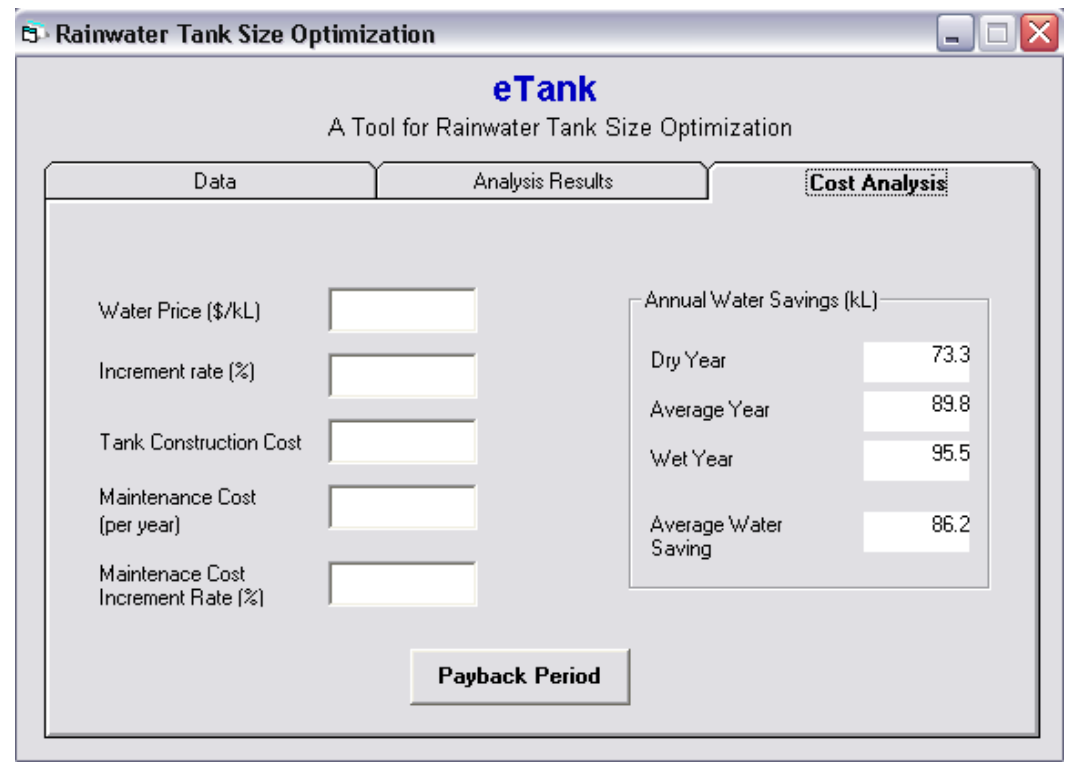

Figure 3 Cost analysis menu

For the same input data, annual water savings were calculated to be $73.3 \mathrm{~kL}, 89.8 \mathrm{~kL} \& 95.5 \mathrm{~kL}$ in a dry year, average year and wet year respectively. For a combination of dry, average and wet years, an overall average annual water savings would be $86.2 \mathrm{~kL}$. Cost analysis calculations were performed with the following input data: water price, $\$ 1.8 / \mathrm{kL}$; water price increment rate, $2 \%$; tank construction cost, $\$ 1500$; tank maintenance cost, \$50/year and tank maintenance cost increment rate, $1 \%$. With this set of data, a payback period for the same tank was calculated to be less than 14 years.

\section{CONCLUSIONS}

Most of the previous rainwater tank related studies focused on a particular geographical locations and/or climate patterns. At present stormwater harvesting systems are proposed and installed without any in-depth analysis of its effectiveness in various climate conditions. A common practice is to use long-term average annual rainfall magnitude to calculate potential rainwater to be saved. However, a stormwater harvesting 
system designed considering average rainfall will not provide much benefit for a critical dry period like 2006. Similarly, an optimum rainwater tank size for a particular area will not be same for another area. In reality, there will be numerous optimal solutions with different combinations of storage volumes, roof sizes and rainwtaer demand. This paper presents development of a comprehensive interactive decision support tool, which will enable an optimum design of rainwater tank size based on contributing roof area, rainwater demand and climate conditions. The tool can be used for any geographical location and also enables calculations of reliability for a particular tank size. Based on daily rainfall data, the developed tool calculates potential reliability, cumulative water savings, cumulative overflow losses and cumulative townwater supply for a particular tank size, connected with a particular roof area under three different climatic conditions. The user-friendly tool can be used for the analysis of effectiveness of a proposed rainwater harvesting system with different storage volumes; with different contributing catchment areas and with different rainfall scenario. It will enable the end-users decision making process easy, effective and knowledgeable.

\section{Cumulative Rainwater Use}

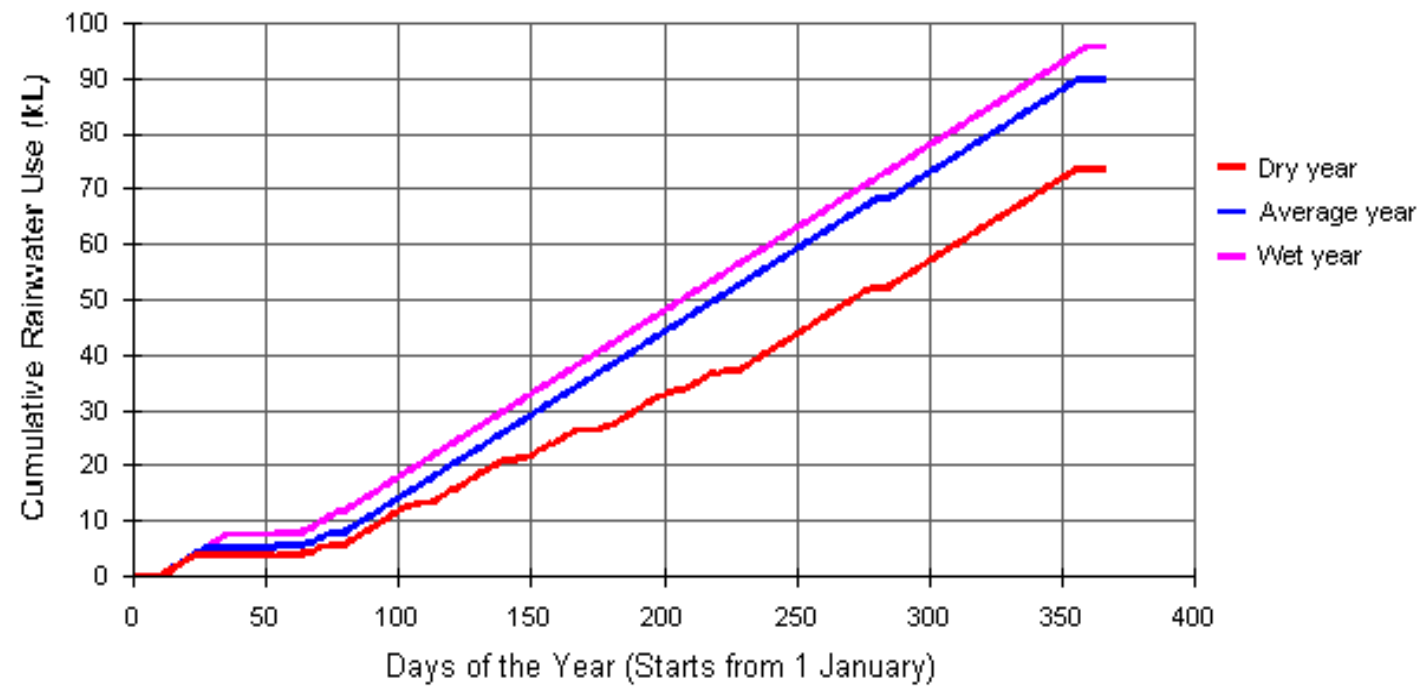

Figure 4

\section{Cumulative Overflow Loss}

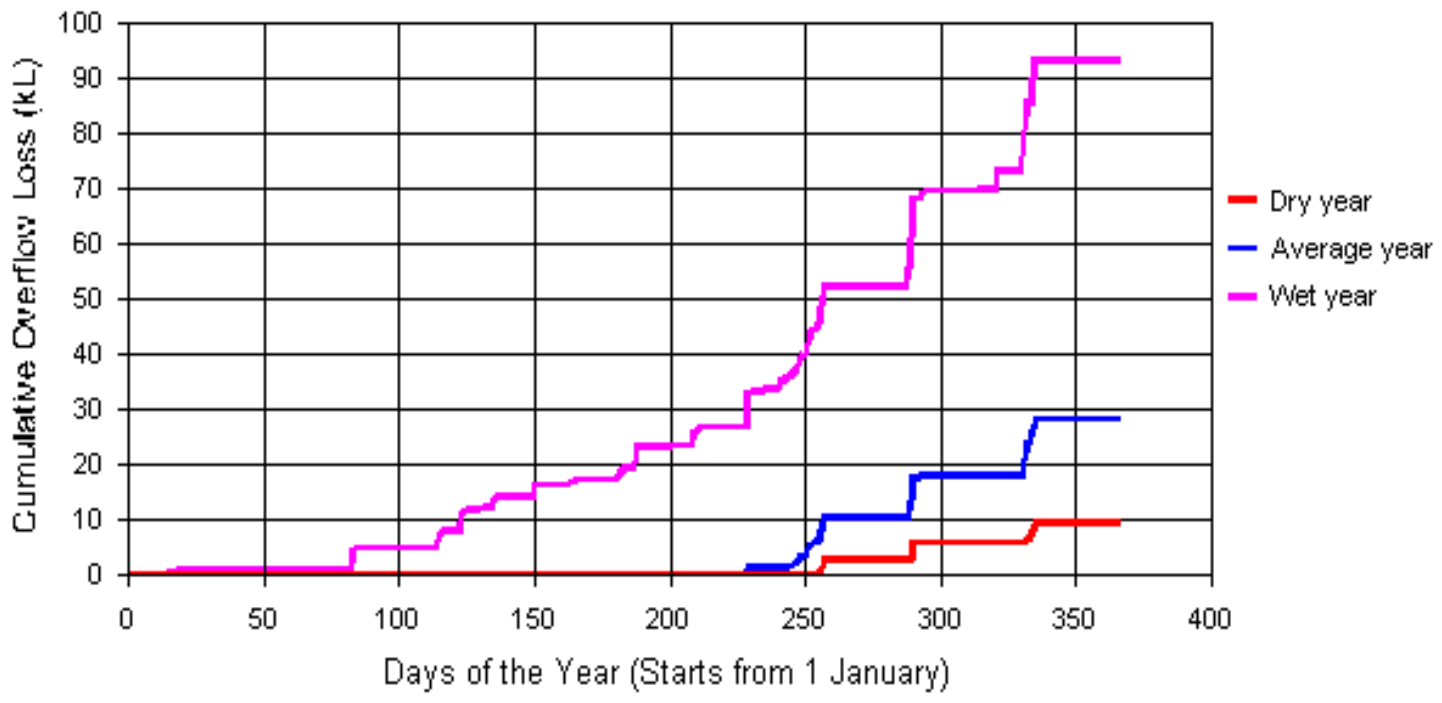

Figure 5

The simple life cycle costing analysis function within the decision support tool calculates cost-effectiveness and payback period of any proposed rainwater tank system. It will facilitate the end-users to perform a costbenefit assessment and eventually will encourage many people/organizations to optimise and install a 
feasible stormwater harvesting system. To keep the tool simple and easy for the users, net present values of the future costs were not considered. For an accurate payback period calculation, it is necessary to convert all future costs into net present values (NPV). The developed tool can be easily upgraded to consider NPVs in any future version. Eventually through the use of this decision support tool, guidelines and specifications for stormwater harvesting can be developed for all the cities in Australia and abroad. Interestingly, there are very few cities who have got such guideline and specifications deduced from a reliable tool.

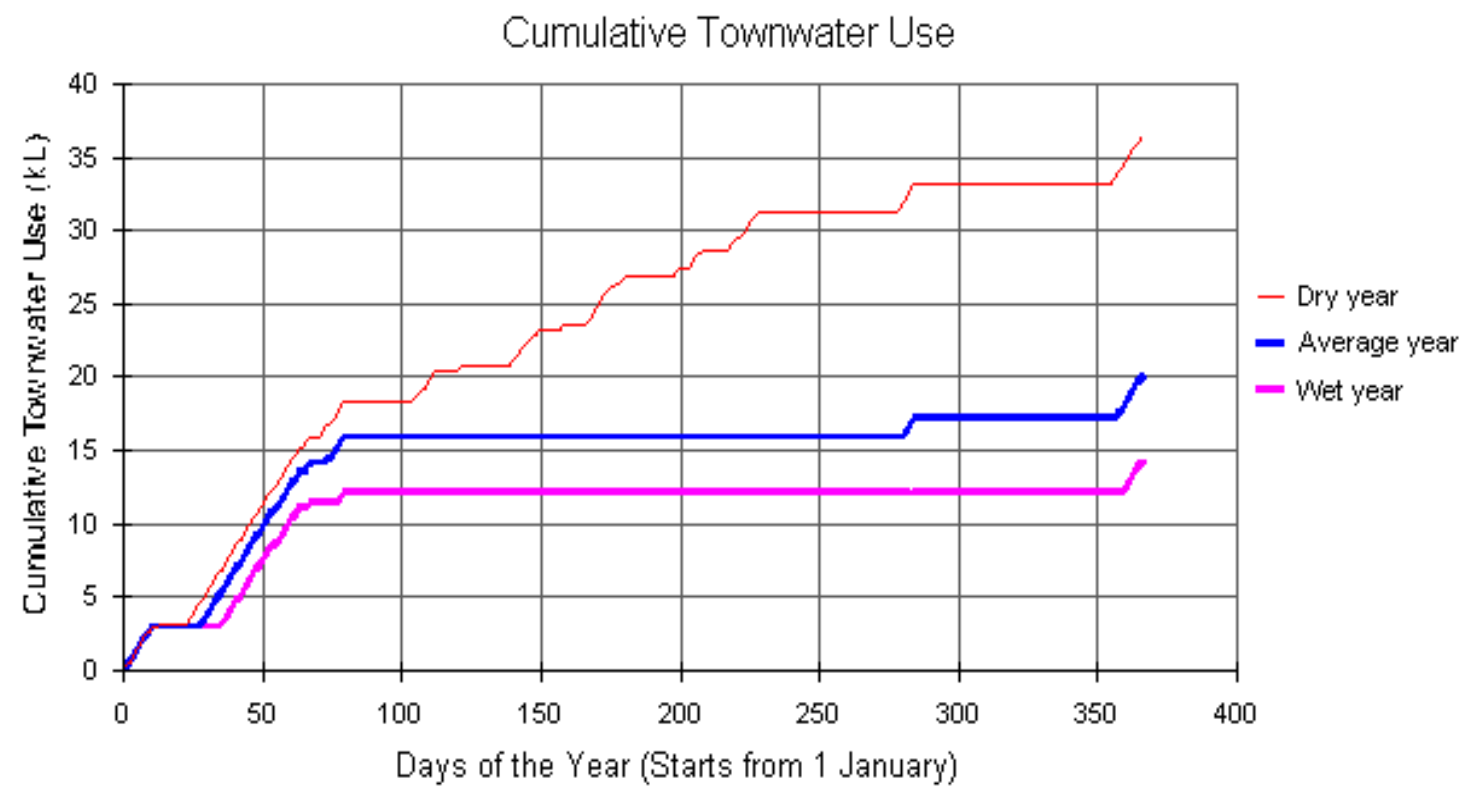

Figure 6

\section{REFERENCES}

Coombes, P. (2007). Rainwater Research, www.rainwaterharvesting.com.au, (Accessed 13 March, 2010).

Coombes, P. and Kuczera, G. (2003). Analysis of the performance of rainwater tanks in Australian capital cities. 28th International Hydrology and Water Resources Symposium, Wollongong, NSW, The Institution of Engineers, Australia.

Fewkes, A. (1999). The use of rainwater for WC flushing: the field testing of a collection system. Building and Environment, 34(6), 765-772.

Ghisi, E., Bressan, D.L. and Martini, M. (2007). Rainwater tank capacity and potential for potable water savings by using rainwater in the residential sector of southeastern Brazil. Building and Environment, 42, 1654-1666.

Ghisi, E., Tavares, D.F. and Rocha, V.L. (2009). Rainwater harvesting in petrol stations in Brasilia: Potential for potable water savings and investment feasibility analysis. Resources, Conservation and Recycling, 54, 79-85.

Imteaz, M.A., Ahsan, A., Naser, J. and Rahman, A. (2011a). Reliability Analysis of Rainwater Tanks in Melbourne using Daily Water Balance Model, Resources, Conservation \& Recycling. DOI: 10.1016/j.resconrec.2011.09.008. (in press)

Imteaz, M.A., Shanableh, A., Rahman, A. and Ahsan, A. (2011b). Optimisation of Rainwater Tank Design from Large Roofs: A Case Study in Melbourne, Australia. Resources, Conservation \& Recycling, 55, 1022-1029. DOI:10.1016/j.resconrec.2011.05.013.

Jenkins, G. (2007). Use of continuous simulation for the selection of an appropriate urban rainwater tank. Australian Journal of Water Resources, 11(2), 231-246.

Khastagir, A. and Jayasuriya, N. (2010). Optimal sizing of rain water tanks for domestic water conservation. Journal of Hydrology, 381: 181-188.

Vaes, G. and Berlamont, J. (2001). The effect of rainwater storage tank on design storms. Urban Water, 3 , 303-307. 